\title{
A combined radiative transfer model for sea ice, open ocean, and atmosphere
}

\author{
Rolf Fuhrhop, ${ }^{1}$ Thomas C. Grenfell, ${ }^{2}$ Georg Heygster, ${ }^{3}$ Klaus-Peter Johnsen, ${ }^{3}$ \\ Peter Schlüssel, ${ }^{4,5}$ Meeno Schrader, ${ }^{6}$ and Clemens Simmer ${ }^{6,7}$
}

\begin{abstract}
A radiative transfer model to compute brightness temperatures in the microwave frequency range for polar regions including sea ice, open ocean, and atmosphere has been developed and applied to sensitivity studies and retrieval algorithm development. The radiative transfer within sea ice is incorporated according to the "many layer strong fluctuation theory" of Stogryn $[1986,1987]$ and T. Grenfell [Winebrenner et al., 1992]. The reflectivity of the open water is computed with the three-scale model of Schrader [1995]. Both surface models supply the bistatic scattering coefficients, which define the lower boundary for the atmospheric model. The atmospheric model computes the gaseous absorption by the Liebe et al. [1993] model. Scattering by hydrometeors is determined by Mie or Rayleigh theory. Simulated brightness temperatures have been compared with special sensor microwave imager (SSM/I) observations. The comparison exhibits shortcomings of the ice model for $37 \mathrm{GHz}$. Applying a simple ad hoc correction at this frequency gives consistent comparison results within the range of observational accuracy. The simulated brightness temperatures show the strong influence of clouds and variations of wind speed over the open ocean, which will affect the sea ice retrieval even for an ice-covered ocean. Simulated brightness temperatures have been used to train a neural network algorithm for the total sea ice concentration, which accounts for these effects. Sea ice concentrations sensed from the SSM/I data using the network and the NASA sea ice algorithm show systematic differences in dependence on cloudiness.
\end{abstract}

\section{Introduction}

Sea ice significantly affects the heat, momentum, and salt fluxes in polar regions and hence influences the global circulation of the ocean and atmosphere. Our ability to quantify these fluxes with sufficient accuracy is limited in part by our inability to accurately determine the spatial and temporal distribution

\footnotetext{
${ }^{1}$ Applied Meteorology and Remote Sensing, Institute for Marine Science, Kiel, Germany.

${ }^{2}$ Department of Atmospheric Sciences, University of Washington, Seattle.

${ }^{3}$ Institute for Environmental Physics, University of Bremen, Bremen, Germany.

${ }^{4}$ Institute for Meteorology, University of Hamburg, Hamburg, Germany.

${ }^{5}$ Now at Institute for Meteorology, Ludwig-Maximilians-University Munich, Munich, Germany.

${ }^{6}$ Institute for Marine Science at the Christian-Albrechts-University, Kiel, Germany.

${ }^{7}$ Now at Institute for Meteorology, Rheinische Friedrich-Wilhelms-University, Bonn, Germany.
}

Copyright 1998 by the American Geophysical Union.

Paper number 97RS03020.

0048-6604/98/97RS-03020\$11.00 of open water, new ice, and young ice [Cavalieri, 1994]. The sea ice cover is also an important indicator for changes of the global climate [Lemke, 1987]. Therefore it is highly desirable to improve the remote sensing methods for sea ice cover, thickness, and type.

Sea ice retrieval from satellite with passive microwave sensors is the most suitable tool because the atmospheric contributions to the radiation signal are much smaller than at other frequencies. However, there is a significant influence from the ocean and atmosphere. Attempts to eliminate (or correct for) this have been made by applying weather filters, for example, to scanning multichannel microwave radiometer (SMMR) observations [Gloersen and Cavalieri, 1986] defining a threshold for the spectral gradient ratio that is used to define the boundary between ice and open water. The following studies have adjusted the threshold for the special sensor microwave imager (SSM/I) [Cavalieri, 1992] and introduced an additional filter to account for the stronger water vapor sensitivity of this instrument [Cavalieri et al., 1995]. Other studies have developed filters for selected geographical regions, for example, for the 
Antartic [Thomas and Heygster, 1996]. The threshold approach for the spectral gradient is applied only over open water or low ice concentrations $(\sim<15 \%)$. A recent study by Oelke [1997] demonstrated the impact of liquid water clouds and the precipitable water also for higher sea ice concentrations.

To study the radiative signature of the polar environment, we combined individual radiation simulation models for the sea ice, ocean, and atmosphere. This integrated model allows us to simulate brightness temperatures for varying surface and atmospheric conditions, including arbitrary ice concentrations and types. From the simulated brightness temperatures the effects on the polarization and spectral gradient ratios due to variations of the atmosphere, ocean, and ice are computed and related to sea ice retrieval. To account for the atmospheric and oceanic influences at arbitrary ice conditions, we derive a neural network-based algorithm for the retrieval of the sea ice concentration.

\section{The Combined Model}

\subsection{Atmospheric Model}

The radiative transfer in the atmosphere is generally described by classical or standard radiative transfer theory. Various methods for the numerical solution of this equation have been developed. For the combined model we adopt the atmospheric model of Simmer [1994], which uses the successive order of scattering method [Liou, 1980]. In the microwave spectrum where the single scattering albedo is rather low, the number of scattering orders to be included is generally less than seven.

The gaseous absorption of oxygen and water vapor is computed with the latest update of an absorption model by Liebe et al. [1993]. The absorption and scattering of nonprecipitating clouds is modeled by Rayleigh theory, and for precipitation, Lorenz-Mie theory is used.

The radiative modeling of the ice-atmosphere or ocean-atmosphere system requires the coupling of the atmosphere and the underlying surface. Both surface models for ocean and ice supply the bistatic scattering coefficients $\gamma$ for a given frequency as function of the polarization ( $r t$, where $r$ and $t$ denote the horizontal or vertical polarization) and the incidence and reflection angles ( $\theta$ and $\theta^{\prime}$, respectively). Since the atmospheric model is restricted to azimuthally independent problems, $\gamma$ is averaged accordingly. The coupling to the atmospheric model is via the surface emission $E$ and reflection $R$. The surface emission expressed in degrees Kelvin is given by [Peake, 1959]

$E_{r}(\theta)=\left(1-\frac{1}{4 \pi} \int\left[\gamma_{r r}\left(\theta, \theta^{\prime}\right)+\gamma_{t r}\left(\theta, \theta^{\prime}\right)\right] \sin \theta^{\prime} d \theta^{\prime}\right) T_{s}$,

where $T_{s}$ is the surface temperature. The reflection of downward directed atmospheric radiation, $T_{A}^{\downarrow}$, by the surface into the direction of observation is calculated from

$R_{r}(\theta)=\frac{1}{4 \pi} \int\left[\gamma_{r r}\left(\theta, \theta^{\prime}\right) T_{A r}^{\downarrow}+\gamma_{r t}\left(\theta, \theta^{\prime}\right) T_{A t}^{\downarrow}\right] \sin \theta d \theta$

The selection of the zenith angles $\left(\theta, \theta^{\prime}\right)$ for the numerical integration is specified by the Gaussian quadrature used to evaluate the integrals in (1) and (2).

The above equations for emission are valid for the open ocean surface because the penetration depth of the microwave radiation is very small (tenths of a millimeter) at microwave frequencies. Thus there is no emission from deeper layers. For sea ice and snow the penetration depth is much larger, and thus the emission temperature may vary with depth. To account for this effect, a radiative transfer approach for the emission temperature would be necessary. However, such a procedure is not yet included in the combined model, and the above equation is assumed to be valid for sea ice as well. To account for the sea ice concentration, the emission and reflection from the ice and ocean are weighted by the fractional sea ice cover.

\subsection{Open Ocean Model}

The scattering properties of the open ocean are described by a three-scale model [Schrader, 1995; M. Schrader and E. Ruprecht, A three-scale model to calculate the reflectivity of a wind-roughened foamcovered sea surface in the microwave frequency range, submitted to Journal of Geophysical Research, 1997]. The first scale is defined by hydrodynamical waves whose radius of curvature is larger than the wavelength of the electromagnetic waves by which the surface is detected. These are primarily gravity waves. The formalism to calculate the appropriate scattering coefficients is given by the Kirchhoff model, assuming specular reflection by the inclined portions of the waves (facet model) weighted by the probability of the occurrence of the slopes [Ulaby et al., 1982]. Owing to the statistical character of this approach to 
the Kirchhoff model, the probability is expressed in terms of the variances of the slopes of the surface waves. These are calculated from the wave spectrum described by the surface wave model of Bjerkaas and Riedel [1979]. The slope variances are then determined by parameterizations calculated from the wave spectrum depending on the friction velocity $u_{*}$ (in $\mathrm{m} / \mathrm{s}$ ) and the electromagnetic frequency $\nu$ (in gigahertz):

$$
\begin{gathered}
\sigma_{\text {upwind }}^{2}\left(u_{*}, \nu\right)=0.0332 u_{*} \log (\nu)^{1.41} \\
\sigma_{\text {crosswind }}^{2}\left(u_{*}, \nu\right)=0.0214 u_{*} \log (\nu)^{1.55} .
\end{gathered}
$$

These parameterizations take into account the reduction of the slope variance at long wavelengths, which is caused by fetch limitation close to the ice edge. To ensure the conservation of energy for the scattering process, a normalization procedure guarantees that the energy scattered from the surface is not larger than the incident energy from any direction.

The second scale is given by the short waves, which would remain in the wave spectrum if the waves of the first scale were removed. These are typically the very short gravity and capillary waves. The first and second scales are separated by the cutoff wavenumber $k_{c}$, which is determined as a function of the electromagnetic frequency and surface stress. The scattering behavior of the second roughness scale is calculated by an approximation of the small perturbation method. It is assumed that the small-scale ripples are perfectly conducting reflectors and that polarization effects can be neglected. This simplifies the formalism and describes the scattering effects of the ripples in a satisfactory manner, as comparisons with a full polarized model have shown [Schrader, 1995]. The roughness parameter of this component of the model is the variance of the amplitude of the small-scale waves $\zeta$, which is determined from the wave spectrum. As was done for the first scale, $\zeta$ is incorporated in the model by a parameterization of the form

$$
\zeta\left(u_{*}, \nu\right)=0.1248 u_{*} e^{-0.0102 \nu} .
$$

The scattering due to the second roughness scale leads to a modification of the Fresnel coefficients that describe the reflectivity of each facet of the first scale.

The third scale incorporates changes in the reflectivity due to whitecaps and foam streaks and is considered separately. The third scale is assumed to occur on each facet, which leads to a further modifi- cation of the reflection. The effective reflection coefficients are given by

$$
R_{\text {eff }}=R_{R}\left(1-f_{w c}-f_{f s}\right)+R_{w c} f_{w c}+R_{f s} f_{f s}
$$

where $R_{R}$ is the combined reflection coefficient of the first and second scale. $R_{w c}$ and $R_{f s}$ are the reflection coefficients of whitecaps and foam streaks, respectively. The coverage of the whitecaps and foam streaks is denoted by $f_{w c}$ and $f_{f s}$. The coverage of the whitecaps is given by an empirical expression that was obtained from cold water data [Monahan and O'Muircheartaigh, 1986]:

$$
f_{w c}=3.4 \times 10^{-2} u_{*}^{3279}
$$

Owing to the frequent occurrence of nonneutral atmospheric stratification conditions in the boundary layer over the open water, the consideration of stability effects is necessary. The coverage of the foam streaks is calculated by an approach that is deduced from measurements over the North Atlantic and the North Sea during springtime for low water temperatures [Ross and Cardone, 1974]:

$$
f_{f}=\left(1+r_{f w}\right) f_{w c}
$$

where $f_{f}$ is the total coverage of foam structures on the water and $r_{f w}$ is the ratio of foam streaks to whitecaps, with $r_{f w}=-1.99+0.25 u_{20}\left(u_{20}\right.$ is the wind speed in $\mathrm{m} / \mathrm{s}$ measured at $20-\mathrm{m}$ height). The reduction in reflectivity due to shadowing effects is taken into account by a shadow function taken from Smith [1967]. Multiple scattering is approximated according to Guissard and Sobieski [1987].

\subsection{Sea Ice Module}

There exist two different analytic approaches to calculate the microwave brightness temperature for sea ice: models based on the solution of the radiative transfer equation and models based on Maxwell's equations assuming random perturbations of the medium dielectric properties. The radiative transfer approach is relatively simple to use, but several problems occur when using the Lorenz-Mie theory to describe the volume scattering: (1) The ice grains and the snow are so closely packed that the scatterers in the vicinity of a particular grain are in its near field, and thus the use of far-field scattering coefficients is inappropriate. (2) Independent scattering by individual particles is assumed, which ignores interference effects between the particles. (3) The ice grains and brine inclusions are usually not spherical. These 
Table 1. Observed Ranges of Input Parameters for the Sea Ice Model and Interval Steps Used for the Sensitivity Analysis

\begin{tabular}{|c|c|c|c|}
\hline Parameter & Range & $\begin{array}{l}\text { Sensitivity } \\
\text { Interval }\end{array}$ & Reference \\
\hline Sea ice density & $700-920 \mathrm{~kg} / \mathrm{m}^{3}$ & $11 \mathrm{~kg} / \mathrm{m}^{3}$ & Eicken et al. [1995] \\
\hline Salinity & $0-16$ ppt & $0.8 \mathrm{ppt}$ & Tucker et al. [1992] \\
\hline Grain size & $4-10 \mathrm{~mm}$ & $1 \mathrm{~mm}$ & Stogryn [1987] \\
\hline Thickness FY & $0.3-2 \mathrm{~m}$ & $7.5 \mathrm{~cm}$ & $\begin{array}{l}\text { World Meteorological } \\
\text { Organization [1989] }\end{array}$ \\
\hline Thickness MY & $2.3-6.1 \mathrm{~m}$ & $7.5 \mathrm{~cm}$ & Tucker et al. [1992] \\
\hline Brine pocket orientation & $0^{\circ}-90^{\circ}$ & $5^{\circ}$ & Stogryn [1986] \\
\hline Brine pocket aspect ratio & 1:1-1:0.000025 & $\cdots$ & Stogryn [1986] \\
\hline Snow density & $224-546 \mathrm{~kg} / \mathrm{m}^{3}$ & $16 \mathrm{~kg} / \mathrm{m}^{3}$ & Garrity [1992] \\
\hline Snow grain size & $0.2-6 \mathrm{~mm}$ & $0.3 \mathrm{~mm}$ & $\begin{array}{l}\text { Barber et al. }[1995] \\
\quad \text { Winebrenner et al. }[1992]\end{array}$ \\
\hline Snow depth on FY A & $4.5-67 \mathrm{~cm}$ & $4.5 \mathrm{~cm}$ & Garrity [1992] \\
\hline Snow depth on MY A & $7.0-70 \mathrm{~cm}$ & $4.5 \mathrm{~cm}$ & Garrity [1992] \\
\hline Snow depth on FY AA & $10-15 \mathrm{~cm}$ & $4.5 \mathrm{~cm}$ & Tucker et al. [1992] \\
\hline Free water content FY & $0-40$ ppt & $2 \mathrm{ppt}$ & Gamty [1992] \\
\hline Free water content MY & $0-70 \mathrm{ppt}$ & $2 \mathrm{ppt}$ & Garrity [1992] \\
\hline
\end{tabular}

Abbreviations are FY, first-year ice; MY, multiyear ice; A, Arctic; and AA, Antarctic.

difficulties lead to unacceptably low brightness temperatures when using classical radiative transfer models, for example, for dry snow at higher frequencies [Stogryn, 1986].

To overcome these problems, the strong fluctuation theory was developed among other approaches. The "many layer strong fluctuation theory" offers the possibility to describe the sea ice and snow by vertical profiles of their microphysical parameters (Table 1). We selected the model of Stogryn [1986, 1987] as implemented by T. Grenfell [Winebrenner et al., 1992] because it represented best, although not exactly, the observed emissivity of 8-cm-thick gray ice in a comparison study of Winebrenner et al. [1992]. The model calculates the volume scattering in the microwave region between 1 and $100 \mathrm{GHz}$. The contribution of surface scattering to the emissivity, which is not taken into account with this model, is very small for most ice types.

Figure 1 shows an example of the model results for multiyear ice. A striking feature of the calculated emissivities are the oscillations with the frequency. Similar oscillations are observed in emissivity versus layer depth curves. They can be explained as coherent reflections at the plane-parallel layer boundaries in the model. In nature, the different ice properties show relatively smooth profiles with depth instead of stratified discontinuities, and thus there are no boundaries for coherent reflection. Natural horizontal variability also tends to smooth such oscillations. As the amplitude of the oscillations is considerably smaller than the variability of the in situ emissivities, also shown in the figure, the oscillations do not hamper the use of the model for emissivity predictions; however, the sensitivity to small changes in frequency or layer depth should be interpreted with care. A modification of the strong-fluctuation-theory model to represent the natural smoothing of these oscillations is currently in progress.

To model the volume scattering by sea ice, the microphysical structure has to be described by a large number of parameters, for example, inhomogeneity size distribution and density, for each layer. This involves many degrees of freedom and the knowledge of parameters which are difficult and costly to measure. Thus it would be desirable to reduce the effective number of input parameters by using relations between them. Several studies have investigated the ice microphysical structure (see Tucker et al. [1992] for a comprehensive compilation). Observed ranges of the input parameters are given in Table 1. The results of these studies indicate that there is no universal relation between any of these parameters, even for a single ice type. This is at least partly due to the fact that the state of the atmosphere during initial ice formation and later determines the ice structure. Thus the high variability in the ice structure is partly caused by the high variability of the atmosphere. It follows that, in principle, no reduction of the input parameters can be achieved by using relations without knowing the history of the atmospheric parameters. 


\section{Comparisons to Ground Truth Data}

While the individual models for sea ice, open ocean, and atmosphere have been validated in earlier studies [Winebrenner et al., 1992; Schrader, 1995; Simmer, 1994], the combination of the individual models into one integrated model needs further validation to quantify the coupling between the atmosphere and the underlying surface.

We selected six test cases from the research expeditions ARKTIS'88 (two cases) and ARKTIS'93 (four cases). Both campaigns took place in the Fram Strait and Greenland Sea [Brümmer, 1989, 1994; Eicken and Meincke, 1994]. The in situ measurements served as input data for the combined model, and the simulated brightness temperatures have been compared with SSM/I observations. One case (case 1) was located far south of the ice edge where sea ice was not present, and thus it was used to verify the open ocean and atmospheric module. The other test cases were located within the sea ice field. Both field experiments were carried out in different seasons. The ARKTIS'88 expedition was in May 1988 when air temperatures were above $-10^{\circ} \mathrm{C}$, while the ARKTIS'93 experiment was carried out in March 1993 accompanied by much colder air temperatures: from $-25^{\circ} \mathrm{C}$ to $-35^{\circ} \mathrm{C}$. Thus the prevailing meteorological conditions during both experiments were quite different.

Sea ice observations were conducted on large multiyear ice floes, but not all input parameters needed for the sea ice model were observed. Only the temperature profile and the thickness of the ice/snow layer were recorded continuously, and there were no observations of the sea ice concentration. Thus simulations have been carried out for sea ice concentrations retrieved from the SSM/I observations using the NASA sea algorithm [Cavalieri, 1992]. We are aware that this implies possible errors due to atmospheric and oceanic effects (see sensitivity analyses). The parameters of the physical structure of the ice, for example, density, grain sizes, air bubbles, and salinity profiles, have been adopted from measurements taken on a representative multiyear ice floe during the ARKTIS'93 experiment. For the ARKTIS'88 test cases, no sea ice microphysical parameters are available. Thus they have been adopted from the ARKTIS'93 observations with snow density and grain size increased somewhat, in order to obtain simulated brightness temperatures close to the SSM/I observations. These modifications are reasonable, because

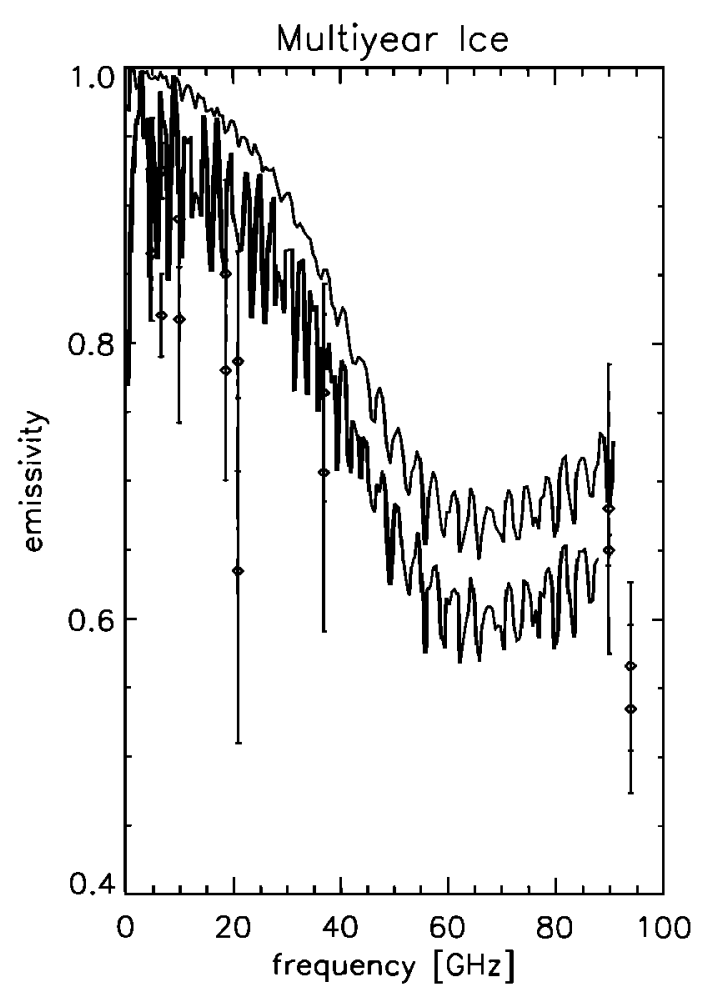

Figure 1. Emissivities of multiyear ice at $50^{\circ}$ incidence angle. The higher values are $\mathrm{V}$-polarized emissivities, and the lower values are H-polarized emissivities. Measurements are from Eppler et al. [1992].

the snowpack in May (1988 case) was older and warmer than in March (1993 case).

While the atmospheric temperature and humidity profiles were measured by radiosondes, the cloud physical properties are not known. Only the synoptic observations are available. To estimate the effect of clouds, the simulations have been carried out with a range of liquid water paths (LWP) and both water and ice phases.

Another uncertainty is the horizontal inhomogeneity of the input parameters. The simulated brightness temperatures represent a point measurement, while the SSM/I observations are horizontally integrated quantities. Because we have no information on the spatial scale of the parameters, we assume that the large-scale variability (10 SSM/I pixels) is indicative for the smaller-scale (one SSM/I pixel). It should be noted that the small-scale variation mainly originates from a change of the snow and ice structure, while the large-scale variability as seen by the SSM/I is, in general, caused by changes of the open water fraction 
Table 2. Mean SSM/I Brightness Temperature $\left(\overline{T_{B}}\right)$, Standard Deviation $(\sigma)$, and Difference to the Simulated Brightness Temperature $\left(\Delta T_{B}\right)$ for Test Cases

\begin{tabular}{|c|c|c|c|c|c|c|c|c|c|c|c|c|c|c|c|c|c|c|c|c|c|}
\hline \multirow{2}{*}{$\begin{array}{c}\text { Chan- } \\
\text { nel }\end{array}$} & \multicolumn{3}{|c|}{ Case 1} & \multicolumn{3}{|c|}{ Case 2} & \multicolumn{3}{|c|}{ Case 3} & \multicolumn{3}{|c|}{ Case 4.1} & \multicolumn{3}{|c|}{ Case 4.2} & \multicolumn{3}{|c|}{ Case 5} & \multicolumn{3}{|c|}{ Case 6} \\
\hline & $\overline{T_{B}}$ & $\sigma$ & $\Delta T_{B}$ & $\overline{T_{B}}$ & $\sigma$ & $\Delta T_{B}$ & $\overline{T_{B}}$ & $\sigma$ & $\Delta T_{B}$ & $\overline{T_{B}}$ & $\sigma$ & $\Delta T_{B}$ & $\overline{T_{B}}$ & $\sigma$ & $\Delta T_{B}$ & $\overline{T_{B}}$ & $\sigma$ & $\Delta T_{B}$ & $\overline{T_{B}}$ & $\sigma$ & $\Delta T_{B}$ \\
\hline $19 \mathrm{~V}$ & 192.8 & 0.7 & -4.8 & 228.6 & 2.1 & -1.2 & 231.1 & 1.4 & 2.2 & 229.6 & 2.1 & -1.2 & 217.9 & - & -0.7 & 236.6 & 1.7 & -1.7 & 234.5 & 54.3 & -5.3 \\
\hline $19 \mathrm{H}$ & 130.1 & 1.3 & -3.7 & 207.1 & 2.9 & 3.2 & 213.0 & 2.3 & 3.8 & 207.3 & 4.8 & 1.1 & 181.3 & - & 5.8 & 205.5 & 2.8 & 4.0 & 197.9 & 97.8 & 0.4 \\
\hline $22 \mathrm{~V}$ & 210.4 & 0.9 & -0.9 & 224.7 & 1.8 & 2.0 & 228.9 & 1.7 & 4.8 & 227.7 & 2.1 & 1.1 & 217.1 & - & 2.9 & 233.7 & 1.6 & 0.8 & 235.2 & 23.4 & -2.2 \\
\hline $37 \mathrm{~V}$ & 217.1 & 1.7 & -2.9 & 214.4 & 1.6 & 12.8 & 218.8 & 1.8 & 13.6 & 219.9 & 2.0 & 9.6 & 217.0 & - & 9.9 & 215.2 & 2.8 & 27.6 & 225.3 & 33.2 & 10.0 \\
\hline $37 \mathrm{H}$ & 167.5 & 3.8 & 4.3 & 197.5 & 2.7 & 13.3 & 205.0 & 2.2 & 11.7 & 202.5 & 3.3 & 8.5 & 187.4 & - & 14.6 & 190.4 & 3.0 & 15.9 & 198.0 & 4.8 & 5.4 \\
\hline $85 \mathrm{~V}$ & 254.3 & 2.5 & 3.2 & 214.1 & 2.6 & 5.2 & 221.6 & 2.5 & -0.4 & 223.0 & 3.5 & -0.9 & 228.4 & - & 2.3 & 210.6 & 4.8 & 2.0 & 226.3 & 6.6 & 7.1 \\
\hline \multirow[t]{2}{*}{$85 \mathrm{H}$} & 232.1 & 5.0 & 2.2 & 196.9 & 2.9 & 5.6 & 209.5 & 2.4 & -1.4 & 207.3 & 4.0 & -2.3 & 208.5 & - & 0.7 & 190.0 & 5.8 & 0.3 & 215.7 & 75.8 & -3.3 \\
\hline & \multicolumn{3}{|c|}{ Case 1} & \multicolumn{3}{|c|}{ Case 2} & \multicolumn{3}{|c|}{ Case 3} & \multicolumn{3}{|c|}{ Case 4.1} & \multicolumn{3}{|c|}{ Case 4.2} & \multicolumn{3}{|c|}{ Case 5} & \multicolumn{3}{|c|}{ Case 6} \\
\hline \multirow{5}{*}{$\begin{array}{l}f_{c} \\
\text { LWP } \\
\text { Clouds } \\
T_{S} \\
v\end{array}$} & \multirow{3}{*}{\multicolumn{3}{|c|}{$\begin{array}{l}0 \% \\
0.1 \mathrm{~kg} \mathrm{~m}^{-2}\end{array}$}} & \multirow{4}{*}{\multicolumn{3}{|c|}{$\begin{array}{l}90 \% \\
0.0 \mathrm{~kg} \mathrm{~m}^{-2} \\
10005 \\
-36^{\circ} \mathrm{C}\end{array}$}} & \multirow{4}{*}{\multicolumn{3}{|c|}{$\begin{array}{l}90 \% \\
0.03 \mathrm{~kg} \mathrm{~m}^{-2} \\
77-7- \\
-27^{\circ} \mathrm{C}\end{array}$}} & \multirow{4}{*}{\multicolumn{3}{|c|}{$\begin{array}{l}85 \% \\
0.03 \mathrm{~kg} \mathrm{~m}^{-2} \\
6605-\end{array}$}} & 65 & & & & & & \multicolumn{3}{|c|}{$70 \%$} \\
\hline & & & & & & & & & & & & & & $03 \mathrm{~kg}$ & $m^{-2}$ & & $0.1 \mathrm{~kg}$ & $m^{-2}$ & & $0.1 \mathrm{~kg}$ & $m^{-2}$ \\
\hline & & & & & & & & & & & & & & 605- & & & 885- - & & & 885- - & \\
\hline & \multirow{2}{*}{\multicolumn{3}{|c|}{$\begin{array}{l}5.0^{\circ} \mathrm{C} \\
16 \mathrm{~m} / \mathrm{s}\end{array}$}} & & & & & & & & & & & $29^{\circ} \mathrm{C}$ & & \multirow{2}{*}{\multicolumn{3}{|c|}{$7 \mathrm{~m} / \mathrm{s}$}} & & $-3^{\circ} \mathrm{C}$ & \\
\hline & & & & \multicolumn{3}{|c|}{$8 \mathrm{~m} / \mathrm{s}$} & \multicolumn{3}{|c|}{$10 \mathrm{~m} / \mathrm{s}$} & \multicolumn{3}{|c|}{$18 \mathrm{~m} / \mathrm{s}$} & \multicolumn{3}{|c|}{$18 \mathrm{~m} / \mathrm{s}$} & & & & \multicolumn{3}{|c|}{$4 \mathrm{~m} / \mathrm{s}$} \\
\hline
\end{tabular}

Observed brightness temperatures are averaged over 10 pixels, except case 4.1 ( 9 pixels) and 4.2 ( 1 pixel). Simulations are for the ice concentrations $\left(f_{c}\right)$ and cloud water path amounts (LWP). Synoptic cloud observations are given by World Meteorology Organization code $\mathrm{NN}_{L} \mathrm{C}_{L} \mathrm{C}_{M} \mathrm{C}_{H}$. Surface temperature and wind speed are denoted by $T_{s}$ and $\nu$, respectively.

and ice type constituents. Standard deviations computed from ground-based measurements on firstyear-ice floes [Grenfell, 1986] show even larger values than those estimated from SSM/I in our study. SSM/I instrument errors have been estimated to about $\pm 3 \mathrm{~K}$ for each channel in a study by Hollinger [1989]. The standard deviation of the observed SSM/I pixels is of about the same order. Thus the differences between simulated and observed brightness temperatures are considered satisfactory as long as the differences do not exceed 4-7 K, depending on the case.

\subsection{Open Ocean Module}

To verify the inclusion of the three-scale ocean model, we use case 1 , where sea ice was not present. The synoptic situation is characterized by a high wind speed $(18 \mathrm{~m} / \mathrm{s})$ and a cloudy sky (advanced very high resolution radiometer (AVHRR) images). The simulations have been carried out for different wind speeds $( \pm 2 \mathrm{~m} / \mathrm{s})$ and liquid water path amounts $\left(0-0.2 \mathrm{~kg} \mathrm{~m}^{-2}\right)$. Close agreement between the simulated and observed brightness temperatures is found for a simulated wind speed of $16 \mathrm{~m} / \mathrm{s}$ and LWP of 0.11 $\mathrm{kg} \mathrm{m}^{-2}$ (Table 2). With these values, all channels, except $19-\mathrm{GHz}$ vertical polarization, are within the expected error range. A liquid water path of about 1.5 $\mathrm{kg} \mathrm{m}^{-2}$ would be required to bring this channel into agreement with the observation. Thus a likely source for the larger difference is variation in the subscale cloudiness within the large satellite footprint at 19 GHz.

\subsection{Sea Ice Module}

The sea ice model has been compared with cases 2-6 (Table 2). The strongest influence on the simulated brightness temperatures originates from the sea ice concentration caused by the large contrast of the emissivity between open water and ice. While the wind speed exerts a large signal on the open ocean part, its effect is reduced when the ice concentration increases. The cloud water content, however, introduces a significant influence on the simulated brightness temperatures.

Owing to the low atmospheric temperatures, it is reasonable to assume an ice phase for the simulated clouds. Snow clouds reduce the brightness temperatures due to scattering, while liquid water clouds increase the brightness temperatures due to emission. We found that the simulation of the ice phase gave smaller differences between the observed and simulated brightness temperatures than did liquid water clouds.

Cases 2, 3, and 4 were located on the same ice floe within a time period of 4 days. Since the meteorological conditions did not change and the temperatures were far below the freezing point, no changes of the 
ice and snow structure have been assumed. For cases 3 and 4 , simulated snow clouds were necessary to reduce the brightness temperatures from the clearsky value, in agreement with the synoptic observations. The best agreement for case 2 was found for clear-sky conditions, also in full agreement with the synoptic observations.

We have also tried to verify that the estimated sea ice concentration using the NASA sea ice algorithm is reasonable. This is possible with case 4 , where the estimated ice concentrations are $85-90 \%$ for nine SSM/I pixels (case 4.1 ) and $65 \%$ for one pixel (case 4.2). The ERS 1 synthetic aperture radar (SAR) image available for this scene (Figure 2) allows an independent test because high wind speeds induced a high open water surface roughness, and thus bright areas in the image correspond to open water. The circles indicate individual SSM/I footprints at $19-\mathrm{GHz}$ horizontal polarization. The ice floe and ship position is marked by an arrow. High SSM/I sea ice concentrations are found for the pixels around the ice floe, while the pixel with $65 \%$ ice concentration is located south of the ice floe with a brightness temperature of 181.3 K (lower left corner of the image). The SAR image also shows decreasing ice concentrations of the same magnitude south to the ice floe position. Thus we assume that the NASA ice concentration retrievals are reasonable.

All simulations for the ice-covered ocean (cases 2-6) yield simulated brightness temperatures at 37 $\mathrm{GHz}$, which are larger than the observed one. Changing the ice input parameters would not lead to better results at $37 \mathrm{GHz}$, but the differences for the other frequencies would increase. In order to use the model for further studies, we have to correct the brightness temperatures at $37 \mathrm{GHz}$. Here this is done simply by multiplying the sea ice reflectivity by 2.0 and 1.5 at vertical and horizontal polarization, respectively. These factors have been derived from the cloud-free case (case 2) to avoid errors due to clouds. Applying this correction to the other cases reduces the differences between observations and simulations at 37 $\mathrm{GHz}$ below $5 \mathrm{~K}$.

\section{Brightness Temperature Sensitivity Analyses}

\subsection{Sensitivity to Atmospheric Parameters}

For a given state of the surface we simulated brightness temperatures with varying atmospheric parameters. The most important quantity is the cloud water content (liquid or ice) and to a minor degree the precipitable water content. Changes of brightness temperature due to varying air temperature can be neglected compared with the variability of the other parameters. To demonstrate the influence of clouds on the sea ice retrieval, we investigated the changes of the polarization ratio (PR) and spectral gradient ratio (GR) defined by

$\mathrm{PR}=\frac{T_{B 19 v}-T_{B 19 h}}{T_{B 19 v}+T_{B 19 h}} \quad \mathrm{GR}=\frac{T_{B 37 v}-T_{B 19 v}}{T_{B 37 v}+T_{B 19 v}}$

Figure 3 shows the simulated variability of $P R$ and GR for three cloud types: thick clouds with cloud droplets up to the size of raindrops, thin clouds with small cloud droplets $(\sim 10 \mu \mathrm{m})$, and snow clouds. The sea ice state is represented by three tie points: open water (OW), totally covered ocean with first-year ice (FY), and multiyear ice (MY). The total sea ice concentration is represented by the distance of a given state of PR and GR to OW, and the fraction of the ice types is given by the ratio of distances to FY and MY. According to the standard weather filters, any pixel with GR $>0.05$ is regarded as ice free. The simulations have been carried out for an open ocean (plus signs) assuming a wind speed of $10 \mathrm{~m} / \mathrm{s}$ and for completely sea ice covered ocean (asterisks) using the ice and snow parameters of case 2 . While the surface parameters have been left constant, the cloud water path (liquid or snow) has been varied from 0.0 to 0.4 $\mathrm{kg} \mathrm{m}^{-2}$ for all three cloud types. The state with no clouds is indicated by the letter $\mathrm{L}$.

Over the open ocean, liquid water clouds decrease PR but increase GR. However, for thick clouds, GR decreases again for LWP values above about $0.15 \mathrm{~kg}$ $\mathrm{m}^{-2}$. In none of these cases, however, does the PG/GR point move into the sea ice range and therefore does not lead to wrong ice concentrations. For a totally ice covered ocean, liquid water clouds cause a shift from multiyear to first-year ice and a small decrease of the total ice concentration. For a partially ice covered ocean (not shown) the effect on the sea ice retrieval depends on the actual surface state, i.e., wind speed, sea ice cover, and ice type. Especially for multiyear ice, liquid water clouds may mimic a higher concentration of first-year ice. These effects are not taken into account by the usual weather filters. The situation is different for snow clouds, which mainly reduce GR but only slightly reduce PR. For the open ocean an erroneous retrieval of ice is produced when exceeding a certain threshold of liquid water path. 


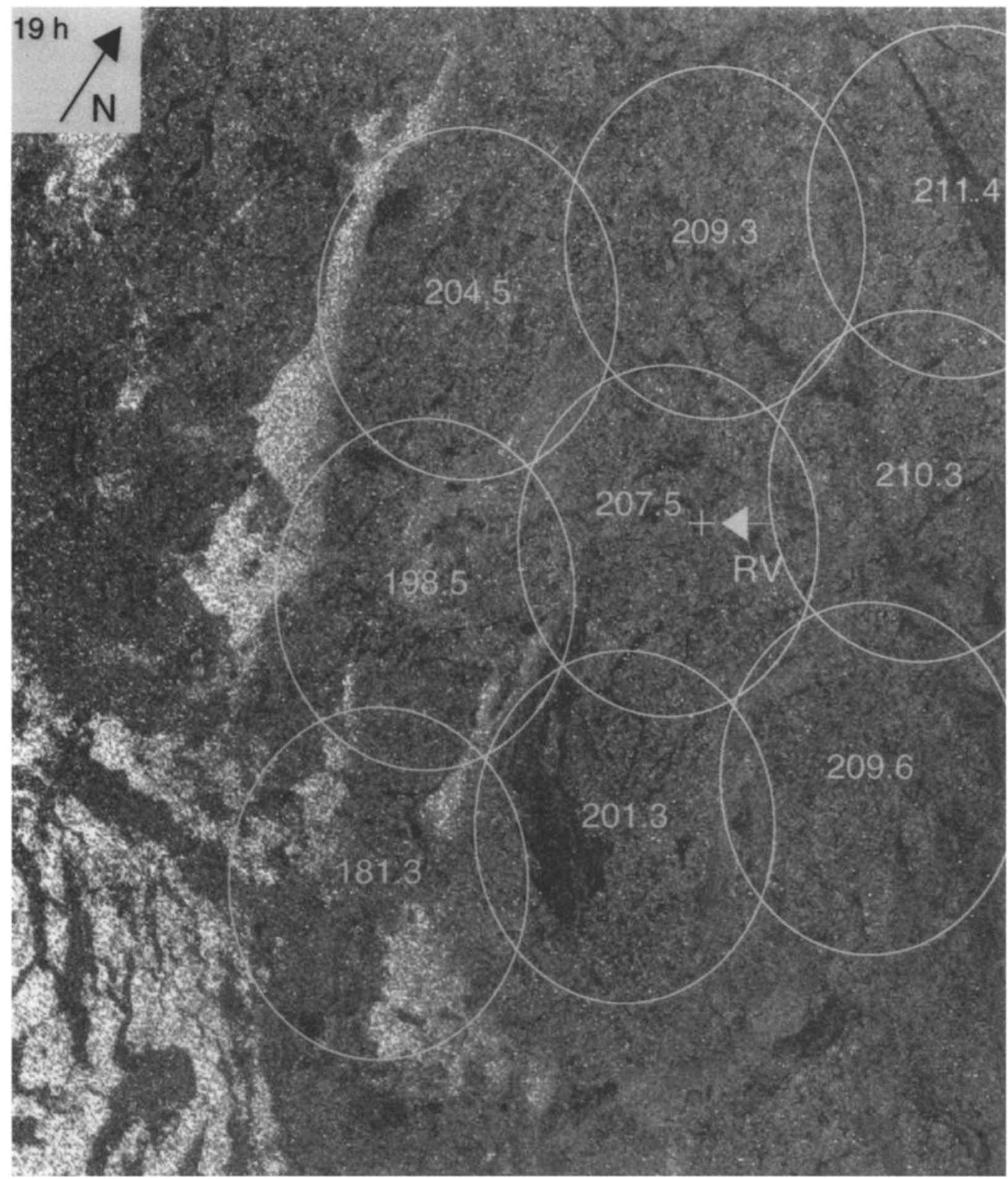

Figure 2. ERS 1 synthetic aperture radar scene of the area around the ice floe station (marked by arrow RV) for case 4. Special sensor microwave imager (SSM/I) brightness temperatures of the 19-GHz horizontally polarized channel are overlain. Circle radius corresponds to $15 \mathrm{~km}$. 

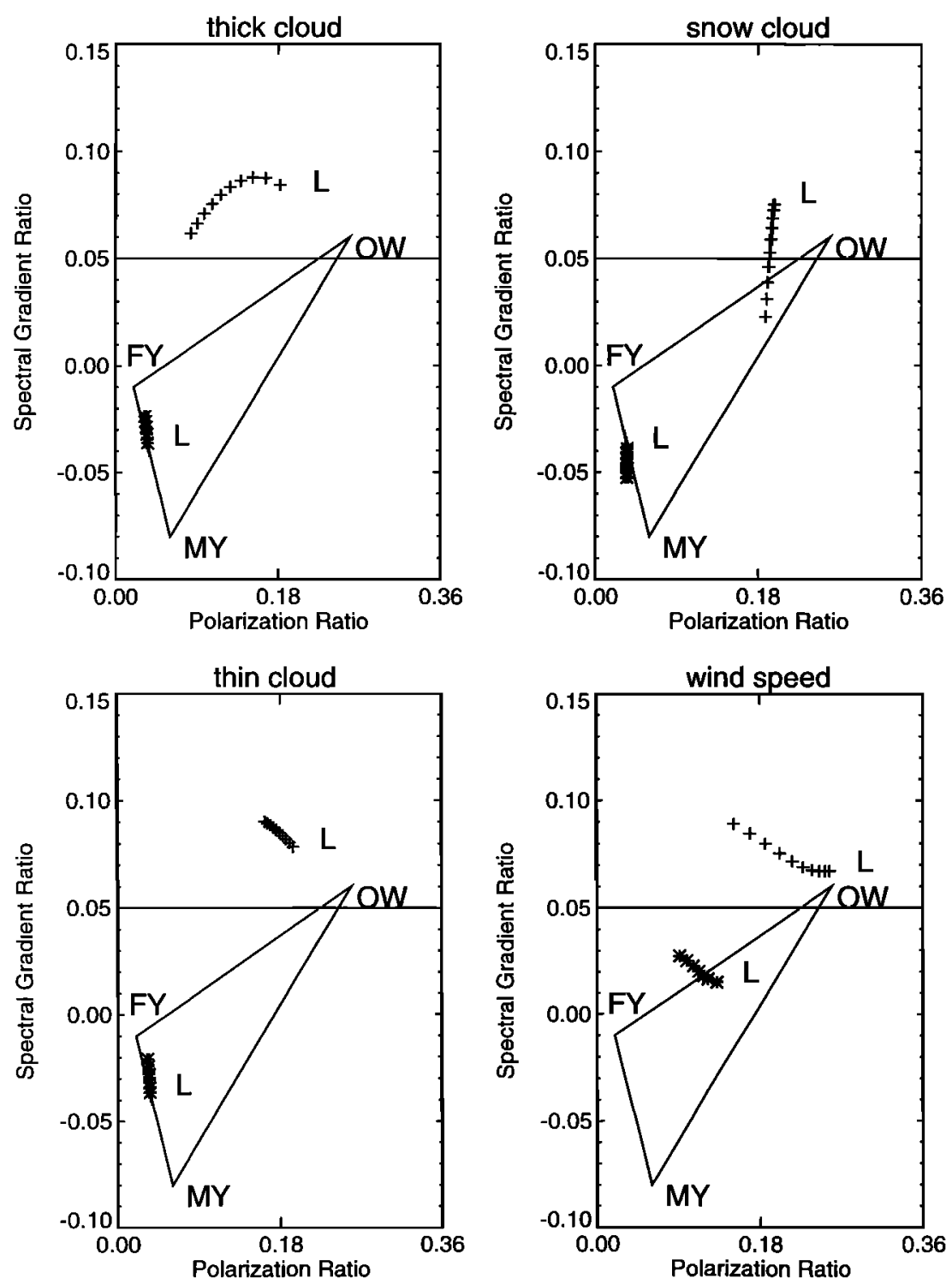

Figure 3. Changes of the polarization and spectral gradient ratio induced by the variation of thick clouds, thin clouds, and snow clouds with liquid water path ranges from 0 to $0.4 \mathrm{~kg} \mathrm{~m}^{-2}$. Changes due to wind speed correspond to the range from 0 to $25 \mathrm{~m} / \mathrm{s}$. Simulations represent the open (plus signs) and totally sea ice covered ocean (asterisks). Tie points for open water, first-year ice, and multiyear ice are denoted by OW, FY, and MY, respectively.

Over sea ice, snow clouds lead to a shift from first-year to multiyear ice, with only a small increase of the total ice concentration.

These simulations clearly demonstrate the influence of atmospheric clouds on the sea ice retrieval. Especially for the partly ice covered ocean, clouds show a significant impact. Because they are not corrected by a threshold filter approach, the clouds lead to spurious retrievals of sea ice. These results are in agreement with a study of Oelke [1997], which was limited to liquid-water clouds only.

\subsection{Sensitivity to Ocean Surface Parameters}

The major signal from the surface arises from the sea ice concentration due to the large emissivity difference between ice and water. The changes in 
Table 3. Ice Layer Structure Used for Multiyear Ice Simulation

\begin{tabular}{|c|c|c|c|c|c|c|c|c|c|}
\hline$d, \mathrm{~m}$ & $T, \mathbf{K}$ & $\rho, \mathrm{g} / \mathrm{cm}^{3}$ & $D_{\mathrm{sn}}, \mathrm{mm}$ & $f_{\text {wat }}$ & $D_{\text {Ice }}, \mathrm{mm}$ & $D_{\text {alr }}, \mathrm{mm}$ & $s, \mathrm{ppt}$ & $\theta, \operatorname{deg}$ & $A$ \\
\hline \multicolumn{10}{|c|}{ Water Layer } \\
\hline-2.50 & 269.9 & 1.000 & .00 & 0.00 & 0.0 & 0.0 & 32.0 & 0.0 & 0 \\
\hline \multicolumn{10}{|c|}{ Ice Layer } \\
\hline-1.58 & 266.1 & .870 & 0.0 & 0.00 & 10.0 & 1.2 & 3.0 & 24.0 & $.250 \mathrm{E}-04^{*}$ \\
\hline-1.02 & 265.7 & .870 & 0.0 & 0.00 & 10.0 & 1.2 & 2.4 & 24.0 & $.250 \mathrm{E}-04$ \\
\hline-.97 & 265.4 & .890 & 0.0 & 0.00 & 10.0 & 1.2 & 1.9 & 24.0 & $.250 \mathrm{E}-04$ \\
\hline-.87 & 265.1 & .890 & 0.0 & 0.00 & 10.0 & 1.2 & 1.4 & 24.0 & $.250 \mathrm{E}-04$ \\
\hline-.77 & 264.8 & .890 & 0.0 & 0.00 & 10.0 & 1.2 & 1.2 & 24.0 & $.250 \mathrm{E}-04$ \\
\hline-.63 & 264.5 & .895 & 0.0 & 0.00 & 10.0 & 1.2 & 0.7 & 24.0 & $.250 \mathrm{E}-04$ \\
\hline-.46 & 264.1 & .895 & 0.0 & 0.00 & 10.0 & 1.2 & 0.3 & 24.0 & $.250 \mathrm{E}-04$ \\
\hline-.38 & 263.7 & .728 & 0.0 & 0.00 & 10.0 & 1.2 & 0.1 & 24.0 & $.250 \mathrm{E}-04$ \\
\hline \multicolumn{10}{|c|}{ Snow Layer } \\
\hline-.20 & 263.5 & .728 & 0.8 & 0.00 & 0.0 & 3.0 & 0.0 & 0.0 & 0 \\
\hline-.15 & 263.3 & .460 & 0.8 & 0.00 & 0.0 & 5.0 & 0.0 & 0.0 & 0 \\
\hline-.10 & 263.1 & .100 & 0.8 & 0.00 & 0.0 & 1.2 & 0.0 & 0.0 & 0 \\
\hline .00 & 263.1 & .100 & 0.8 & 0.00 & 0.0 & 1.2 & 0.0 & 0.0 & 0 \\
\hline
\end{tabular}

${ }^{*}$ Read $.250 \mathrm{E}-04$ as $.25 \times 10^{-4}$.

Parameters are layer depth $d$; temperature $T$; density $\rho$; snow liquid water fraction $f_{\text {wat }}$; grain diameters for ice $D_{\text {1ce }}$ and snow $D_{\text {sn }}$; air bubble diameter $D_{\text {arr }}$; bulk salinity s; brine pocket orientation $\theta$; and aspect ratio $A$ (diameter/vertical extent).

simulated brightness temperatures range from 10 to $130 \mathrm{~K}$ from an open ocean to a totally ice covered ocean, depending on frequency. The open water signal is mainly determined by the wind speed. Assuming a wind speed range from 0 to $25 \mathrm{~m} / \mathrm{s}$, the absolute changes in brightness temperatures are about 3 times smaller than for the ice concentration. Increasing wind speed decreases PR and increases GR (Figure 3). For a partially ice covered ocean, high wind speeds lead to a higher ice concentration and a shift from multiyear ice to first-year ice, while over the ice-free ocean, no effects on the ice retrieval occur. Compared with these effects, changes in the sea surface temperature and salinity are an order of magnitude smaller and can be neglected.

\subsection{Sensitivity to Sea Ice Parameters}

The parameter intervals used for the sensitivity calculations are defined as about $5 \%$ of the observed variance (Table 1 ). We find that within these intervals the modeled brightness temperatures vary nearly linearly. The sensitivity analyses are applied to three different ice types with and without a snow layer: dark nilas (thin ice), first-year ice, and multiyear ice. While dark nilas is seldom found on horizontal scales of spaceborne passive microwave sensors, it has been observed with ground-based sensors in field studies. To account for the frost flowers found on dark nilas, a thin snow layer could be used.

As an example, the input structure of a typical multiyear ice is given in Table 3 . The most important impact on the brightness temperatures originates from changes of the upper ice or snow layer. The most pronounced sensitivities are summarized in Table 4 in order of priority and can be explained as follows:

1. The first sensitivity is snow-free water content (multiyear and thin ice). Because of the high dielectric constant of water and its high absorption, even a small fraction of liquid water in the snow reduces the penetration depth. The high absorption causes high emission (Kirchhoff law), resulting in increased brightness temperatures.

2. The second is snow density and snow grain size

Table 4. Summary of Sea Ice Sensitivity Analysis

\begin{tabular}{|c|c|c|c|}
\hline Ice Type & $\begin{array}{l}\text { Most Sensitive } \\
\text { Parameters }\end{array}$ & $\begin{array}{l}\text { Frequency } \\
\text { Dependence }\end{array}$ & Polarization \\
\hline Multiyear Ice & $\begin{array}{l}\text { snow-free water } \\
\text { snow density } \\
\text { snow grain size }\end{array}$ & $\begin{array}{l}\text { decreasing } \\
\text { decreasing } \\
\text { increasing, } \\
\text { changing sign }\end{array}$ & $\begin{array}{l}\text { H, V } \\
\text { H } \\
\text { H, V }\end{array}$ \\
\hline First-Year Ice & $\begin{array}{l}\text { snow density } \\
\text { snow grain size }\end{array}$ & increasing & $\begin{array}{l}\text { H } \\
\text { H, V }\end{array}$ \\
\hline $\begin{array}{l}\text { Dark nilas } \\
\text { with snow }\end{array}$ & $\begin{array}{l}\text { snow density } \\
\text { bubble diameter } \\
\text { salinity } \\
\text { snow-free water }\end{array}$ & $\begin{array}{l}\text { decreasing } \\
\text { decreasing }\end{array}$ & $\begin{array}{l}\text { H, V } \\
\text { H, V } \\
\text { H, V } \\
\text { H, V }\end{array}$ \\
\hline $\begin{array}{l}\text { Dark nilas } \\
\text { without snow }\end{array}$ & $\begin{array}{l}\text { bubble diameter } \\
\text { density } \\
\text { ice salinity }\end{array}$ & & $\begin{array}{l}\text { H, V } \\
\mathrm{H} \\
\mathrm{H}, \mathrm{V}\end{array}$ \\
\hline
\end{tabular}

Most sensitive parameters are in order of priority. 
(in all ice types). Increased density or particle size means increased scattering, i.e., decreased emissivity. If the density or particle size of the scatterers becomes too high, however, the medium tends to become optically thick. In this case we expect lower sensitivity at higher frequencies, as described below.

3. The third is air bubble diameter (dark nilas with and without snow). In general, the air bubble concentration in dark nilas is very low. Increasing air bubble diameter in the ice increases the scattering and thus decreases the observed brightness temperature, provided that an opaque snow cover is not present.

4. The fourth is salinity (dark nilas with and without snow). Both the dielectric constant and the absorption coefficient of the ice increase with increasing salinity. With a thin snow cover (e.g., dark nilas) this sensitivity decreases at higher frequencies because of the increasing scattering by the snow. A thick snow cover (first-year and multiyear ice) completely suppresses this sensitivity.

Changes of PR and GR due to variations of snow density and grain size are shown in Figure 4. Increasing the grain size of the lower snow layer (triangles) increases. GR and PR, which mimics a shift from multiyear ice to first-year ice and a decrease of the total ice concentration. In contrast, increasing the grain size of the uppermost snow layer (plus signs) decreases GR and thus mimics a higher fraction of multiyear ice. The estimate of total ice concentration remains almost unchanged because $P R$ is almost unchanged. An increase of the snow density of the upper layer (crosses) decreases PR, which corresponds to a smaller total ice concentration as well as an increased fraction of multiyear ice. Note that the reference state (letter $R$ ) of our simulated multiyear ice is between the first-year and multiyear tie points. This is not necessarily a limitation of the ice model or the specified input data. The tie points are defined from satellite observations, which represent the largescale state of the sea ice, including all variability of the snow and ice microphysical structure. The simulated reference state represents a local observation. Note that the drop of GR for increasing snow grain size of the top snow layer shifts the reference point significantly closer to the multiyear ice point.

\section{Retrieval of Sea Ice Concentration}

The sensitivity analysis shows that clouds and wind speed have a significant impact on PR and GR. This

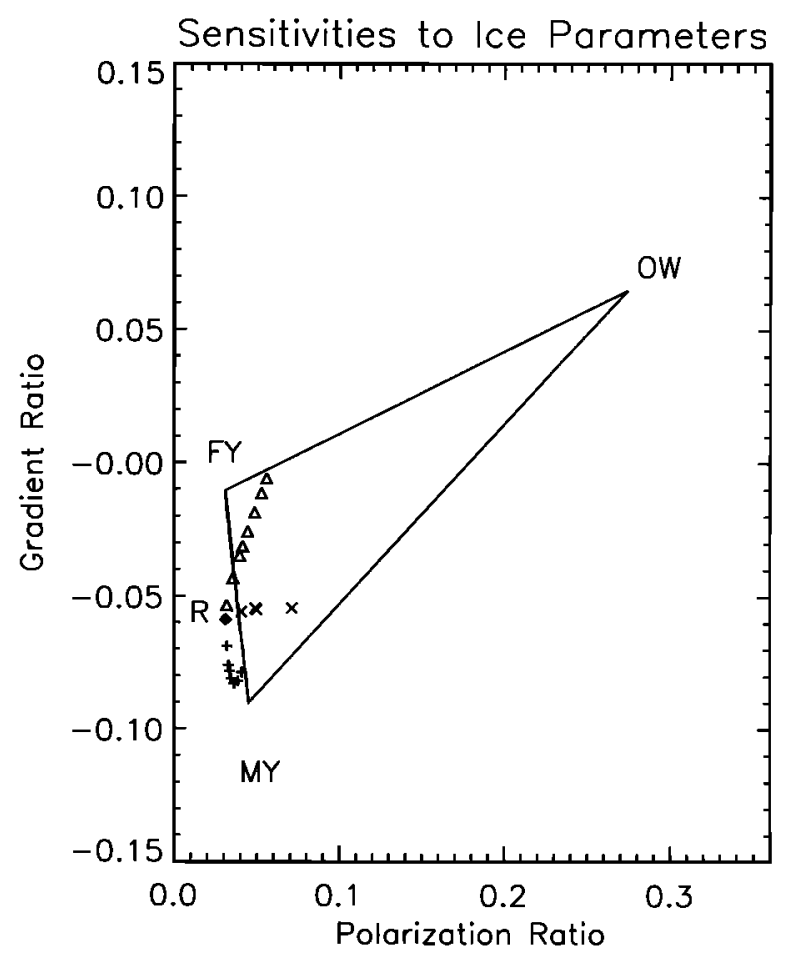

Figure 4. Influence of different microphysical parameters of dry multiyear ice on the polarization and gradient ratio. Also shown are the tie points of first-year ice, multiyear ice, and open water from Cavalieri et al. [1995]. Triangles indicate the snow grain diameter in the lower layer varying from 1.3 to $1.8 \mathrm{~mm}$, and plus signs and indicate the snow grain diameter in the upper layer varying from 0.55 to 1.05 $\mathrm{mm}$; crosses indicate the density of the uppermost snow layer varying from 0.1 to $0.3 \mathrm{~g} / \mathrm{cm}^{3}$, and diamonds indicate the multiyear ice tie point of the undisturbed data.

will affect the retrieval of sea ice based on both ratios, as, for example, in the NASA ice algorithm. To consider the open ocean and atmospheric effects, the retrieval algorithm has to take into account their influence. A useful and unbiased approach is to use a neural network, which is able to learn the effects without defining an a priori threshold. The neural network was trained with 700 simulations of brightness temperatures for different sea ice types, varying sea ice concentration and atmospheric and oceanic conditions, and the performance was estimated against a test data set of 300 simulations. The training rms error for sea ice concentration $(0.96 \%)$ differs only slightly from the test data set $(1.02 \%)$. When applying the neural network (NN) and NASA algorithm to the SSM/I observations of the test cases (10 pixels for each case), systematic differences occur 


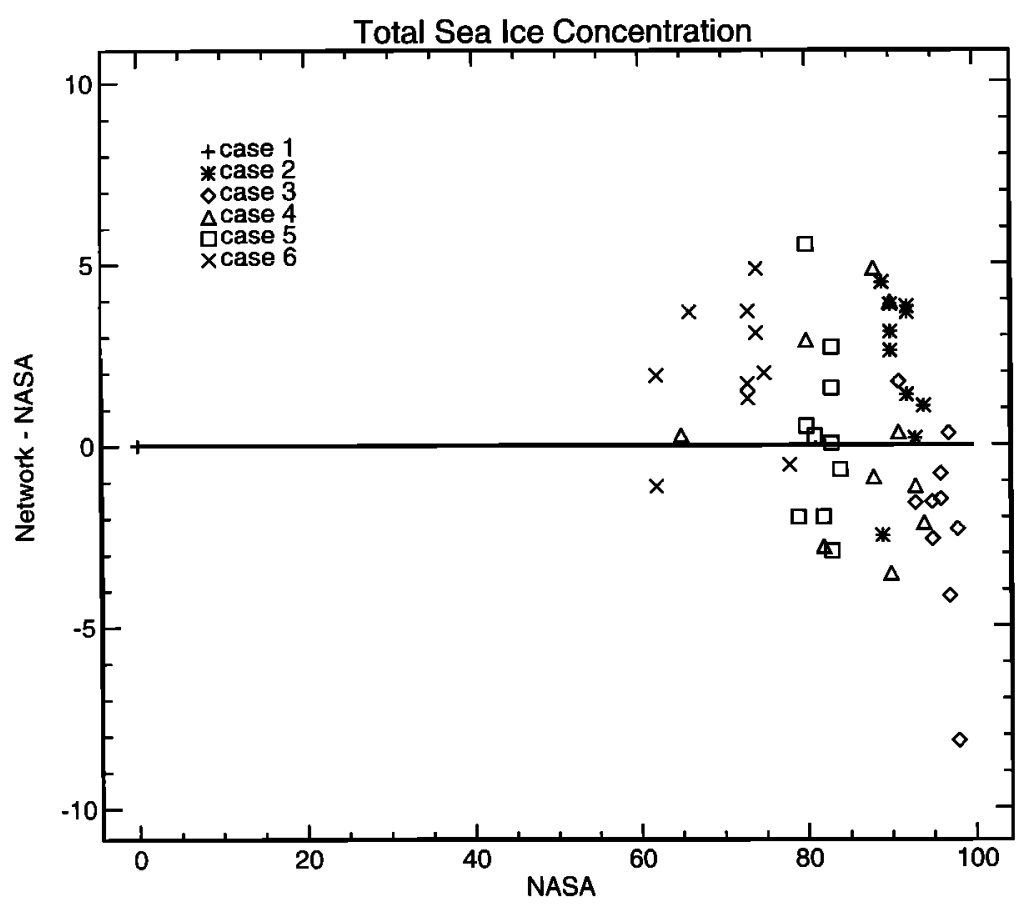

Figure 5. Differences of sea ice concentration retrieved by NASA and neural network algorithm from $\mathrm{SSM} / \mathrm{I}$ observations of the test cases.

(Figure 5). For case 2 (denoted by asterisks) the NASA algorithm estimates a mean value of $91 \%$ ice concentration, which differs from the neural network mean estimation of $93 \%$. Note that for nine of 10 pixels the neural network gives a higher concentration. For case 3 (denoted by diamonds) the neural network again estimates $93 \%$ ice concentration, while the NASA algorithm retrieves a mean value of $96 \%$. For this case, eight of 10 pixels give a lower concentration when the neural network is applied. Moreover, the ice concentrations for first-year and multiyear ice estimated with the NASA algorithm are quite different for both cases. The average first-year ice concentrations for case 2 and 3 are $53 \%$ and $68 \%$, respectively. The multiyear ice concentration decreases from $38 \%$ for case 2 to $28 \%$ for case 3 . These changes are more than about twice as large as the total ice concentration changes estimated from the NASA algorithm. Such changes of the ice composition for such a large area (10 SSM/I pixels) within 2 days are very unlikely (H. Eicken, personal communication, 1996). A major difference between these cases, however, is that the sky was cloud-free for case 2 but cloudy for case 3 . Thus the changing sea ice concentrations computed from the NASA algorithm could also be explained by clouds. This application should be regarded as a demonstration of a promising approach and a first step toward improved sea ice retrieval.

\section{Summary and Conclusions}

A combined radiative transfer model to simulate the radiative signature at microwave frequencies for ice in the polar regions has been developed. The combined model includes the effects of variations in the atmosphere, open ocean, and sea ice. The model has been compared with in situ observations of the surface and atmosphere, and SSM/I measurements. However, owing to the limited ground truth data, this validation has only regional and limited seasonal significance. The comparison exhibits shortcomings of the sea ice model at $37 \mathrm{GHz}$, which have been corrected using a simple ad hoc approach. The source for this error has not been identified, but it indicates that reflectivities at other frequencies than validated may also be in error. Thus the model needs further validation. The in situ data necessary for this task have to fulfill certain requirements. Because satellite observations are highly sensitive to the sea ice con- 
centration, this parameter has to be observed with the highest possible accuracy. Atmospheric parameters should include the cloud cover and type, as well as the cloud water phase. The relevant sea ice parameters are given in Table 4. Emphasis should be put on (1) the variability of these parameters and (2) the mixing of different surface characteristics such as melt puddles, surface roughness, etc., within the footprint of the spaceborne passive microwave sensors. Concerning item 1, Eicken et al. [1995] have shown for level summer multiyear ice in the Eurasian sector of the Arctic Ocean that the variability on the scales of meters and tens of meters of the ice properties is comparable to the one of scales of hundreds of kilometers. This kind of investigation should be extended to other regions, seasons, and ice types. Since item 2 seems to be a main cause for the regional variability of microwave ice signatures, these surface parameters should also be included in in situ measurements intended for comparison with spaceborne observations.

The sensitivity analysis clearly shows the effects of varying atmospheric, open ocean, and sea ice parameters on the polarization and spectral gradient ratios. Our results are qualitatively in agreement with other studies [e.g., Oelke, 1997] but have been extended to snow clouds. The weather filters developed by Gloersen and Cavalieri [1986] for SMMR and SSM/I analysis are limited to areas of open water or low sea ice concentration. The sensitivity studies presented here, however, show a significant effect also for larger ice concentrations. Hence a weather filter is needed that can be applied independently of the ice concentration. A neural network algorithm trained for atmospheric and oceanic influences is an appropriate tool to perform this task. The differences in the retrieved ice concentrations between our network and the NASA algorithm are very likely caused by clouds. However, to assess the quality of the network algorithm, ground truth observations with high accuracy are necessary. Even small differences in the retrieved ice concentrations could have a large effect on the energy fluxes between the atmosphere and ocean. The heat exchange between the ocean and atmosphere is much smaller in the presence of an ice cover. Thus at high ice concentrations the fluxes for a given area are very sensitive to the ice concentration. At this stage our algorithm should be treated as a demonstration of a promising approach to improve the sea ice concentration retrieval from passive microwave measurements. The next-level algorithm ap- plicable on global or at least hemispheric scale will need considerably more training data, including a larger range of ice, ocean, and atmosphere conditions. This will also make it possible to train the network to sense different ice types.

Acknowledgments. Thanks are given to Rene Ramseier and Hajo Eicken for their helpful discussions and contributions and to two anonymous reviewers for their valuable remarks. We especially thank Fritz Wagner for supplying the neural network software. Thanks also to Josef Noll for supervising this study and for his many suggestions. This study was carried out under ESA/ESTEC contract 11198/ 94/NL/CN.

\section{References}

Barber, D. G., S. P. Reddan, and E. F. LeDrew, Statistical characterization of the geophysical and electrical properties of snow on landfast first-year sea ice, J. Geophys. Res., 100(C2), 2673-2686, 1995.

Bjerkaas, A. W., and F. W. Riedel, Proposed model for the elevation spectrum of a wind-roughened sea surface, $A P L$ Tech. Dig., 1328, 31 pp., 1979.

Brümmer, B., Arktis 1988 field phase report, Reihe B: Tech. Abh. 6, Hamb. Geophys. Einzelschriften, Univ. Hamb., 1989.

Brümmer, B., Arktis 1993 report on the field phase with examples of measurements, Reihe A: Meteorol. 11, Ber. Zentrum Meeres Klimaforschung, Univ. Hamb., 1994.

Cavalieri, D. J., NASA sea ice validation program for the Defense Meteorological Satellite Program special sensor microwave imager: Final report, NASA Tech. Memo. 104559, 1992.

Cavalieri, D. J., A microwave technique for mapping thin sea ice, J. Geophys. Res., 99(C6), 12,561-12,572, 1994.

Cavalieri, D. J., K. M. St. Germain, and C. T. Swift, Reduction of weather effects in the calculation of sea-ice concentration, J. Glaciol., 41(139), 455-464, 1995.

Eicken, H., and J. Meincke, The Expedition ARKTIS-IX/1 of RV "Polarstern" in 1993, Tech. Rep. 134, Alfred Wegener Inst. for Polar and Mar. Res., Bremerhaven, Germany, 1994.

Eicken, H., M. Lensu, M. Lepparanta, W. B. Tucker, A. J. Gow, and O. Salmela, Thickness, structure, and properties of level Summer multiyear ice in the Eurasian sector of the Arctic Ocean, J. Geophys. Res., 100(C11), 22,69722,710, 1995.

Eppler, D. T., et al., Passive microwave signatures of sea ice, in Microwave Remote Sensing of Sea Ice, Geophys. Monogr. Ser., vol. 68, edited by F. D. Carsey, pp. 47-71, AGU, Washington, D. C., 1992.

Garrity, C., Characterization of snow on floating ice and case studies of brightness temperature changes during the onset of melt, in Microwave Remote Sensing of Sea Ice, 
Geophys. Monogr. Ser., vol 68, edited by F. D. Carsey, pp. 313-328, AGU, Washington, D. C., 1992.

Gloersen, P., and D. J. Cavalieri, Reduction of weather effects in the calculation of sea ice concentration from microwave radiances, J. Geophys. Res., 91(C3), 39133919, 1986.

Grenfell, T. C., Surface-based passive microwave observations of sea ice in the Bering and Greenland Seas, IEEE Trans. Geosci. Remote Sens., GE-24(3), 378-382, 1986.

Guissard, A., and P. Sobieski, An approximate model for the microwave brightness temperature of the sea, Int. J. Remote Sens., 8(1), 1607-1627, 1987.

Hollinger, J. P., DMSP special sensor microwave/imager calibration/validation: Final report, vol. I, technical report, Naval Res. Lab., Washington, D. C., 1989.

Lemke, $P$., A coupled one-dimensional sea ice-mixed layer model, J. Geophys. Res., 92(C12), 13,164-13,172, 1987.

Liebe, H. J., G. A. Hufford, and M. G. Cotton, Propagation modeling of moist air and suspended water/ice particles at frequencies below $1000 \mathrm{GHz}$, in AGARD 52nd Specialist Meeting of the Electromagnetic Wave Propagation Panel, pp. 3-1-3-10, Advis. Group for Aerosp. Res. and Dev., Brussels, Belgium, 1993.

Liou, K. N., An Introduction to Atmospheric Radiation, Academic, San Diego, Calif., 1980.

Monahan, E. C., and I. G. O'Muircheartaigh, Whitecaps and the passive remote sensing of the ocean surface, Int. J. Remote Sens., 7(5), 627-642, 1986.

Oelke, C., Atmospheric signatures in sea-ice concentration estimates from passive microwaves: Modelled and observed, Int. J. Remote Sens., 18, 1113-1136, 1997.

Peake, W. H., Interaction of electromagnetic waves with some natural surfaces, IRE Trans. Antennas Propag., AP-7, S324-S329, 1959.

Ross, D. B., and V. Cardone, Observations of oceanic whitecaps and their relation to remote measurements of surface wind speed, J. Geophys. Res., 79(3), 444-452, 1974.

Schrader, M., Ein Dreiskalenmodell zur Berechnung der Reflektivität der Ozeanoberfläche im Mikrowellenfrequenzbereich, Tech. Rep. 274, Berichte aus dem Inst. für Meereskunde an der Christian-Albrechts-Univ., Kiel, Germany, 1995.

Simmer, C., Satellitenfernerkundung hydrologischer Parameter der Atmosphäre mit Mikrowellen, Verlag Dr. Kovač, Hamburg, Germany, 1994.

Smith, B. G., Geometrical shadowing of random rough surface, IEEE Trans. Antennas Propag., 15(5), 668-671, 1967.

Stogryn, A., A study of the microwave brightness temperature of snow from the point of strong fluctuation theory, IEEE Trans. Geosci. Remote Sens., GE-24(2), 220-231, 1986.
Stogryn, A., An analysis of the tensor dielectric constant of sea Ice at microwave frequencies, IEEE Trans. Geosci. Remote Sens., GE-25(2), 147-158, 1987.

Thomas, C. H., and G. C. Heygster, Individual weather correction for Antarctic sea ice concentration from SSM/I data, in IGARSS'96: 1996 International Geoscience and Remote Sensing Symposium, pp. 1788-1790, IEEE Press, Piscataway, N. J., 1996.

Tucker, W. B., III, D. K. Perovich, A. J. Gow, W. F. Weeks, and M. R. Drinkwater, Physical properties of sea ice relevant to remote sensing, in Microwave Remote Sensing of Sea Ice, Geophys. Monogr. Ser., vol 68, edited by F. D. Carsey, pp. 9-28, AGU, Washington, D. C., 1992.

Ulaby, F. T., R. K. Moore, and A. K. Fung, Microwave Remote Sensing, Active and Passive, vol. II, Radar Remote Sensing and Surface Scattering and Emission Theory, Addison-Wesley, Reading, Mass., 1982.

Winebrenner, D. P., et al., Microwave sea ice signature modeling, in Microwave Remote Sensing of Sea Ice, Geophys. Monogr. Ser., vol. 68, edited by F. D. Carsey, pp. 137-175, AGU, Washington, D. C., 1992.

World Meteorological Organization, WMO sea-ice nomenclature, Tech. Rep. WMO/OMM/BMO, 259, suppl. 5, Geneva, 1989.

R. Fuhrhop, Applied Meteorology and Remote Sensing, Institute for Marine Science, Düsternbrooker Weg 20, D-24105 Kiel, Germany. (e-mail: rfuhrhop@ifm.unikiel.de)

T. C. Grenfell, Department of Atmospheric Sciences, University of Washington, Box 351640, Seattle, WA 981951640. (tcg@atmos.washington.edu)

G. Heygster and K.-P. Johnsen, Institute for Environmental Physics, University of Bremen, FB1 Box 330440, D-28334, Bremen, Germany. (e-mail: heygster@physik.uni-bremen.de; johnsen@physik.uni-bremen.de)

P. Schlüssel, Institute for Meteorology, LudwigMaximilians-University Munich, Theresienstrasse 37, D-80333 Muenchen, Germany. (e-mail: st220sch@stws04.meteo. physik.uni-muenchen.de)

M. Schrader, Institute for Marine Science at the Christian-Albrechts-University, Düsternbrooker Weg 20, D-24105 Kiel, Germany. (e-mail: 106461.2045@compuserve. com)

C. Simmer, Institute for Meteorology, Rheinische Friedrich-Wilhelms-University, Auf dem Hügel 20, D-53121 Bonn, Germany. (e-mail: csimmer@uni-bonn.de)

(Received March 27, 1997; revised October 16, 1997; accepted October 27, 1997.) 